\title{
DISSOLUÇÃO DE FRONTEIRAS E A EXPERIÊNCIA TRANSICIONAL EM SOLAR STORMS, DE LINDA HOGAN
}

\author{
CAROLINE GARCIA DE SOUZA ${ }^{1}$ \\ UFRGS \\ MARTA RAMOS OLIVEIRA ${ }^{2}$ \\ UFRGS
}

\begin{abstract}
RESUMO:O presente trabalho analisa a experiência transicional no romance Solar Storms, publicado pela escritora nativo-americana Linda Hogan (Chickasaw) em 1995. A obra narra a jornada de Angela, uma mestiça indígena órfã que retorna à terra de seus antepassados na tentativa de desvendar sua história e de religar os fragmentos de um passado parcialmente obscuro. Ao longo da narrativa, percebe-se um processo de gradual desconstrução de categorias - temporais, físicas, espaciais - e de superação das relações dicotômicas que opõem, por exemplo, indivíduo e comunidade, interioridade e exterioridade, o mundo humano e o não humano. Esse movimento se dá na direção de uma dissolução das falsas fronteiras e no sentido de uma integração total.
\end{abstract}

PALAVRAS-CHAVE: Solar Storms; fronteiras; experiência transicional; integração.

ABSTRACT: This article analyses transitional experience in Solar Storms, a novel published by Native American writer Linda Hogan (Chickasaw) in 1995. The novel depicts the journey taken by Angela, an orphan mixed blood who returns to the land of her ancestors in the hope of finding out about her history and reconnecting the fragments of a partially unknown past. The narrative presents a process of gradual deconstruction of temporal, physical and spatial categories, as well as an overcoming of dichotomic relations that oppose, for instance, individual and community, inside and outside, the human and non-human worlds. This movement leads towards the dissolution of false boundaries and the achievement of a total integration.

KEYWORDS: Solar Storms; boundaries; transitional experience; integration.

\footnotetext{
1 Graduanda em Letras pela Universidade Federal do Rio Grande do Sul. E-mail: garciadesouza.carol@gmail.com.

2 Professora do Instituto de Letras da Universidade Federal do Rio Grande do Sul , onde leciona disciplinas de literatura e cultura norte-americanas e orienta estágios de tradução na área de literatura indígena. Sua dissertação, entitulada "The Politics of Memory in Harold Pinter's AshestoAshes", e sua tese, "Weaving Life Stories: Healing Selves in Native American Autobiographical Narratives", estão disponíveis através do Portal SABi. E-mail: marta.ramos.oliveira@gmail.com .
}

Espaço Ameríndio, Porto Alegre, v. 8, n. 2, p. 49-68, jul./dez. 2014. 


\section{Introdução}

Solar Storms, segundo romance da escritora nativo-americana Linda Hogan, retrata a jornada de Angela, uma mestiça indígena órfã, em busca de seus parentes e de sua história após uma vida inteira mudando-se de uma casa adotiva a outra, assombrada por um passado obscuro e um conhecimento fragmentado de si mesma. A narrativa apresenta um complexo processo de cura em que a personagem principal vai aos poucos se aprofundando em seu passado, tanto individual quanto tribal, descobrindo os laços que a unem a uma história coletiva e, em última instância, ao universo como um todo. $\mathrm{Na}$ primeira parte de sua jornada, Angela deixa Oklahoma e viaja a um pequeno vilarejo chamado Furlsland, local de residência de sua bisavó Agnes, de sua tataravó Dora Rouge e de Bush, a primeira esposa de seu avô, com quem posteriormente ela vem a estabelecer uma ligação bastante profunda. Ela também acaba por encontrar sua mãe biológica, Hannah, cujo passado repleto de violências e abusos acaba por transformá-la em gelo, por roubar sua alma e por, mais tarde, fazê-la projetar essa mesma violência sobre sua filha recém-nascida. Da breve relação com a mãe, Angela ainda carrega as marcas na forma de cicatrizes faciais, marcas essas que representam um passado desconhecido, fragmentado e de grande sofrimento.

Assim como em outras de suas obras, Solar Storms constrói-se na gradual dissolução de relações dualistas que permeiam nossas vidas e sociedade. Esforçando-se por "romper a dicotomia cultura/natureza e curar a alienação entre os mundos humano e não-humano"3 (WALTER, 2006, p. 9), Hogan busca resgatar o que, no romance, é descrito como o antigo pacto estabelecido, há muito tempo, entre os dois universos, quando as pessoas ainda podiam conversar com os animais e água e terra eram uma só. Dialogando, em certa medida, com fatos pertinentes à realidade, como o James Bay Project e os impactos da construção de uma série de hidrelétricas no noroeste de Quebec na década de 1970, a autora faz questão de afirmar, contudo, que se trata de um trabalho de ficção, sendo que "qualquer semelhança a eventos, locais ou pessoas -

\footnotetext{
3 Traduções do inglês feitas pela autora do artigo. Texto original: "[T]o break down the culture/nature dichotomy and heal the alienation between the human and nonhuman worlds".
} 
mortas ou vivas - reais é inteiramente coincidente" 4 (CASTOR, 2006, p. 158). Em seu romance, as personagens engajam-se na luta contra a construção de uma represa, na fronteira entre os Estados Unidos e o Canadá, que acarretará, para além dos profundos danos ambientais, um impacto devastador nas vidas de todas as tribos habitantes daquele território e muito além. As quatro personagens principais, dessa forma, unem-se em uma jornada de canoa por águas que levam ao norte, a um local denominado Two-Town Post, a fim de reestabelecer laços de memórias e tentar impedir a realização desse empreendimento.

Nesse sentido, o presente artigo analisa a desconstrução de fronteiras em Solar Storms e o consequente processo de dissolução dos falsos dualismos que pretendem opor natureza e cultura, indivíduo e paisagem, o mundo humano e o não humano. Permeada em diversos níveis pelo conceito de liminaridade, a narrativa explora a experiência da fenda e da separação sob a perspectiva da conectividade. Na obra, a personagem principal engaja-se em um movimento de integração, percebendo o universo em sua plena unidade como algo compartilhado por todos os seres que o habitam e presente em todos eles. A viagem das quatro mulheres, por fim, torna-se uma jornada de progressivo transbordamento que culmina com a superação dos limites que restringem o eu, o corpo e o espírito e que, artificialmente, dividem o tempo entre as categorias de passado, presente e futuro.

\section{A experiência comunal como expansão e integração}

Quando Angela decide iniciar a busca por sua mãe e parentes nativos, ela acredita que a chave de sua cura encontra-se no desvelar de seu passado, na compreensão dos mistérios nele contidos e desenhados na sua própria pele através de cicatrizes, desencadeando, assim, um processo de desfragmentação do "eu". Entretanto, ao longo da narrativa, ela vai aos poucos mergulhando mais fundo na terra de suas "avós", nas memórias e histórias nela traçadas, nas pessoas que a compartilham, nos seus laços, percebendo-se como parte orgânica de algo maior e entendendo que as respostas a suas questões encontram-se antes na

\footnotetext{
4 "Any resemblance to actual events or locales or persons, living or dead, is entirely coincidental".
} 
integração coletiva do que na realização individual. Sua própria existência passa a ser estendida a uma esfera mais ampla que a alimenta de sentido.

Afastando-se das perspectivas ocidentais que desde sempre permearam sua vida, ela passa a conceber a si própria como parte de algo maior, que compreende desde sua família e comunidade até o universo como um todo. Essa mudança em direção a um pensamento holístico e coletivo pode ser apreendida em diferentes níveis narrativos. $\mathrm{Na}$ esfera do enredo, um movimento progressivo de integração é percebido através da gradual transposição de fronteiras que separam, por exemplo, o mundo humano e o não humano, indivíduo e comunidade, sujeito e paisagem, sobretudo ao longo da viagem de canoa em direção ao norte, durante a qual as quatro mulheres estabelecem uma ligação profunda e quase orgânica. Da mesma forma, esse processo também se faz sentir a nível linguístico, através do constante atravessamento da experiência sócio-histórica por uma perspectiva cosmológica mais ampla, que entende a paisagem e seus elementos não como sujeitos e/ou objetos estáticos e imutáveis mas, ao invés disso, destaca sua constituição como movimento, transição, interminável transformação:

Talvez as raízes do sonho se encontrem no solo do dia, ou no coração, ou em outro lugar sem palavras, mas quando se unem umas às outras e crescem, são como as sementes de hidrogênio e as sementes de oxigênio que juntas criam o oceano, o lago e o gelo. Dessa forma, as plantas e eu nos fundimos (HOGAN, 1997, p. $171)^{5}$.

Do mesmo modo, o processo de dissolução de fronteiras vivenciado por Angela também acarreta, temporalmente, a extensão de seu futuro individual ao futuro da comunidade, possibilitando-a visualizar-se e, sobretudo, entender-se como igualmente responsável por aquilo que ultrapassará sua existência individual. Em direção oposta a essa perspectiva, os homens brancos - sobretudo os responsáveis pelo projeto da hidrelétrica, no romance -apresentam uma visão de

\footnotetext{
5"Maybe the roots of dreaming are in the soil of dailiness, or in the heart, or in another place without words, but when they come together and grow, they are like the seeds of hydrogen and the seeds of oxygen that together create ocean, lake, and ice. In this way, the plants and I joined each other".
} 
mundo considerada míope, sendo incapazes de apreender o resultado futuro de suas ações na medida em que seu modo de vida fragmentado e individualista não thes permite ter uma compreensão integrada do mundo. A batalha travada em torno da construção das represas e suas consequências, desse modo, transforma-se em uma luta entre diferentes perspectivas já condenada desde o início, uma tentativa falha de diálogo em que há um grande diferencial de poder.

Sua experiência de viver inserida em uma comunidade, sobretudo durante a estadia no norte, em Two Town Post, na casa de Tulik, um conhecido de Dora Rouge que as acolhe por um tempo, também a leva a reelaborar sua compreensão do privado. O compartilhamento de um espaço comunal e a vivência coletiva funcionam de modo a realocar a esfera do privado, não mais associado a um vazio espacial externo, essencialmente superficial, mas fortificado no aprofundamento da experiência interior:

De início, eu odiava não ter privacidade na casa lotada de Tulik, mas então eu fui aprendendo que privacidade, assim como beleza, era superficial. (...) Fui me acostumando à nossa proximidade. $E$ aos nossos silêncios ${ }^{6}$ (HOGAN, 1997, p. 235).

Angela vai entendendo que, para verdadeiramente mergulhar nas águas do "eu", é necessário superar as false boundaries - ou as falsas divisas - disseminadas pelo pensamento ocidental, cuja concepção de privado é estritamente associada a um isolamento físico. O viver comunal, nesse sentido, impele-a a afastar-se das superfícies - da pele, do corpo, da casa, entre outros - num movimento de progressiva submersão e desbravamento interior. De acordo com Walter,

essa inserção na cultura/natureza tribal, onde tudo 'se fundia e unia' (177), onde 'os antigos' podiam ser ouvidos 'nas canções dos lobos' (176) possibilita que Angela visualize uma realidade alternativa sem fronteiras ${ }^{7}$ (WALTER, 2006, p. 10).

\footnotetext{
6 "At first I hated having no privacy in Tulik's crowded place, but then I learned that privacy, like beauty, was skin-deep. [...] I grew accustomed to our closeness. And to our silences".

7 "[T] his falling into tribal culture/nature, where 'everything merged and united' (177), where 'the old ones' can be heard 'in the songs of wolves' (176) enables Angela to envision an alternative reality without borders".
} 
Seu passado, presente e futuro passam a alinhar-se ao passado, presente e futuro da tribo, permitindo-a compartilhar suas histórias ancestrais, memórias e sonhos.

\section{Corpo, paisagem e trans-bordamento}

Do mesmo modo, outras fronteiras tiveram de ser dissolvidas a fim de que Angela alcançasse uma integração total. Depois de sua chegada a Furlsland, local de residência de suas "avós", a personagem vai gradativamente se engajando em uma jornada interior que se evidencia, por exemplo, na importância cada vez menor atribuída às cicatrizes de seu rosto. De acordo com Nancy Shoemaker (2002):

O corpo como um recipiente é outra metáfora básica a partir da qual imaginamos os outros como tendo fronteiras, até mesmo objetos aparentemente não limitados como, para usar o exemplo de Lakoff e Johnson, montanhas e esquinas de ruas. De acordo com os autores (1980:25), 'os objetivos humanos geralmente reclamam-nos a imposição de fronteiras artificiais que tornem os fenômenos físicos discerníveis tais quais nós somos: entidades limitadas por uma superfície'8 (SHOEMAKER, 2002, p. 62).

Nesse sentido, a concepção do corpo como um recipiente que apresenta limites definidos e que se constitui a partir de relações de interioridade/exterioridade precisava ser dissolvida, bem como as fronteiras da individualidade. Uma das principais etapas desse processo dá-se no momento em que Angela, acidentalmente, derruba o espelho do banheiro e quebra-o em inúmeros pedaços. A partir desse instante, não mais podendo recorrer com frequência à sua imagem refletida no espelho e em outros tipos de superfícies, a personagem não vê outra escolha a não ser passar a imaginar-se a si própria, "juntamente com as partes e fragmentos de estórias, como se fossem todas elas pedaços de um todo quebrado se movendo, tentando se mover, em direção à

\footnotetext{
8 "The body as a container is another basic metaphor from which we imagine others having boundaries, even such seemingly unbounded objects as, to use Lakoff and Johnson's examples, mountains and street corners. As they say (1980:25), 'Human purposes typically require us to impose artificial boundaries that make physical phenomena discrete just as we are: entities bounded by a surface"'.
} 
totalidade" 9(HOGAN, 1997, p. 85). Finalmente, ela afirma desistir "de todas as superfícies, até mesmo da tensa pele da água"10 (HOGAN, 1997 , p. 85). Em relação às pessoas, ela começa "a ler seus olhos para enxergar que tipo de alma elas têm"11 (HOGAN, 1997, p. 85). A figura do espelho associada à falta de profundidade de uma superfície plana e planificadora - é recorrente ao longo da narrativa. Significativamente, a metáfora do espelho é também utilizada para caracterizar os olhos vazios de sua mãe Hannah, que parecem retratar, em última instância, a ausência de uma alma. Juntamente com sua aparência externa selvagem, eles podem ser interpretados à luz de uma subjetividade roubada e não mais existente, seu corpo passando a representar um mero recipiente de massacres, estupros e torturas infligidos a toda a comunidade. Ela é, sob tal perspectiva, apenas pele, casca, superfície, com seu próprio nome partilhando e reforçando seu caráter espelhado, na medida em que Hannah forma a exata mesma palavra quando lida de trás para frente.

Enquanto Hannah funciona como uma personagem que ressoa "a história e o espírito da paisagem de Two-Town"12 (CASTOR, 2006, p. 163), agindo de certo modo como um receptáculo que absorveu uma gama de violações, abusos e violências infligidos à comunidade toda, chegando mesmo a repeti-las posteriormente na forma de agressões à sua filha bebê, Angela supera a dor da ausência de amor da mãe na medida em que aprende a navegar entre fronteiras e a transformar antigos traumas em alimento de resistência. Diferentemente de sua mãe, ela engaja-se em um movimento de apagamento de bordas, incluindo aquelas intrínsecas ao próprio corpo. De modo inverso ao processo descrito por Shoemaker, em que formatos e modos de orientação essencialmente humanos são transferidos ao mundo externo e seus componentes, o corpo de Angela e, até mesmo, sua subjetividade passam a ser moldados por elementos da paisagem. Ao longo de sua viagem de canoa em direção ao norte, a personagem vai aos poucos incorporando qualidades da água, como a fluidez, a diluição e a

\footnotetext{
9 "[A]long with the parts and fragments of stories, as if it all was part of a great brokenness moving, trying to move, toward wholeness".

10 "[A]ll surfaces, even the taut skin of water".

11 "[S]he began to read their eyes to see what kind of souls they had".

12 "[T]he history and the spirit of the landscape of Two Town".
} 
profundidade. Ela chega mesmo a desenvolver a habilidade de enxergar através da superfície da água até locais que a visão humana comum nunca alcançaria. No ápice desse processo, a personagem descreve a viagem empreendida por ela e suas avós nos seguintes termos:

De alguma maneira, eu sabia que iria perder uma parte de mim mesma nessa viagem, como se, no momento em que nos jogássemos na água, eu sairia para fora de minha própria pele. Era uma forma de morte. E eu estava com medo. Antes disso, temia que a noite e o sono pudessem me engolir, que me afogasse na escuridão; mas agora meus medos passaram a conter lagos e rios e coisas com dentes ${ }^{13}$ (HOGAN, 1997, p. 159).

Sua jornada, nesse sentido, constrói-se através da suspensão gradual de todos os tipos de fronteiras. As quatro mulheres embarcam num estado de atemporalidade no qual não mais existem categorias. "Quarta foi o último dia que chamamos pelo nome"14 (HOGAN, 1997, p. 70). Angela também passa a conceber Deus como sendo todas as coisas, humanas e não humanas: "foi assim que eu vim a entender, mais tarde, que Deus era tudo aquilo abaixo dos meus pés, tudo aquilo cercado de água; ele estava no ar, e não havia espaço vazio"15 (HOGAN, 1997, p. 170). E, a partir daí, ela percebe que as pessoas e a terra ainda são capazes de se comunicar, sendo que os sonhos formam um de seus laços mais profundos e funcionam, muitas vezes, como mapas reveladores de correntes de água e de onde se pode encontrar alimentos, por exemplo. Esses mapas são de natureza diferente daqueles criados pelos colonizadores, que mostram superfícies rasas e vazias como espelhos, incapazes de apreender a terra em toda a sua dimensão. Os mapas conhecidos através dos sonhos e das histórias orais manifestam a linguagem que humanos e animais ainda compartilham: "Esses sonhos eram chamados de mapas da fome e quando eles [as pessoas do norte] os seguiam, encontravam sua presa.

\footnotetext{
13 "Somehow, I knew I would lose a part of myself on this journey, as if, when we cast off into water, I would step outside my skin. It was a kind of dying. And I was afraid. Before then I'd feared that night and sleep could swallow me, that I would drown inside darkness, but now my fears grew to contain lakes and rivers and things with teeth".

14 "Wednesday was the last day we called by name".

15 "[T] hat was how I came later to understand that God was everything beneath my feet, everything surrounded by water; it was in the air, and there was no such thing as empty space".
} 
Era a linguagem que animais e humanos tinham em comum"16 (HOGAN, 1997, p. 170).

Além disso, a jornada de Angela culmina com a dissolução temporária de sua identidade enquanto indivíduo. Citando Octavio Paz, Hogan afirma, em uma de suas entrevistas, que "assim que o homem adquiriu consciência de si mesmo, ele se desligou do mundo natural e construiu para si outro mundo dentro de si mesmo"17 (ARNOLD, 2001, p. 51). Angela, ao longo de sua viagem, experienciou um movimento inverso a esse, de religamento e retorno ao universo natural. A certa altura, a personagem consegue superar os limites do seu "eu" social, originado em última instância das relações estabelecidas com os outros no processo de alteridade. A dissolução desse limite, consequentemente, dilui as fronteiras de Angela enquanto indivíduo detentor de uma identidade definida e fechada, possibilitando-a retornar a ser molécula, água, poeira solar: "Esqueci de respirar, nadando como se, uma vez mais, como antes de nascer, eu possuísse guelras. Nesse momento, relembrei ser peixe. Lembrei ser oxigênio e hidrogênio, pássaro ecarcaju"18 (HOGAN, 1997, p. 179). Transbordando suas próprias margens, seu corpo volta a participar do universo enquanto parte de um todo maior e interconectado, com cada molécula sendo libertada e voltando a partilhar das memórias de ser mineral, animal e planta.

Esse processo de dissolução de fronteiras não é vivenciado apenas por Angela. Suas avós são igualmente submetidas a tal movimento. Bush, por exemplo, vai gradativamente abrindo-se como lírios, tornando-se "tão ilimitada como uma vez fora limitada pela casa, pele e água"19 (HOGAN, 1997, p. 176). Agnes, por sua vez, aproxima-se ainda mais do espírito do urso que a acompanha desde criança e cuja pele ela passou a carregar consigo após sua morte. Quanto à Dora Rouge, sua jornada de retorno à terra de seus antepassados e de encontro da morte possibilita-a enxergar o que não pode ser visto pelos outros "enquanto

\footnotetext{
16 "These dreams they called hunger maps and when they followed those maps, they found their prey. It was the language animals and humans had in common".

17 "'[A]s soon as man acquired consciousness of himself, he broke away from the natural world and made himself another world inside himself".

18 "I forgot to breathe, swimming as if once again, as before birth, I had a gill slit. In that moment, I remembered being fish. I remembered being oxygen and hydrogen, bird and wolverine".

19 "[A]s uncontained as she had previously been contained by skin, house, island, and water".
} 
a terra e as silenciosas brumas avançam"20 (HOGAN, 1997, p. 177). As quatro mulheres integram-se com a terra e entre si, navegando sobre águas e territórios compartilhados com divindades e sobre os quais tudo é igualmente sagrado e ativo no movimento constante de criação.

\section{O tempo curvando-se sobre si mesmo e a experiência da criação}

Em diversos sentidos a viagem das quatro mulheres representou um movimento de ruptura e abertura de fendas. Em relação ao tempo, as personagens submeteram-se a uma certa suspensão na qual a linearidade "passado, presente e futuro" foi rompida e substituída por uma presentificação total. Através do adentramento num espaço transicional onde categorias e definições não mais funcionavam, deu-se um processo de convergência de temporalidades e amalgamento do antes, agora e depois num único evento, circunscrito no momento presente. "Foi nessa brecha no tempo que nós entramos, e esse era um local entre mundos"21 (HOGAN, 1997, p. 177). Passou-se a vivenciar um estar entre dois mundos, o humano e o não humano. "Não mais havia distinção precisa entre escuridão e luz. Água e ar tornaram-se o mesmo, bem como a água e a terra no caldo barrento da criação"22 (HOGAN, 1997, p. 177). As águas por elas navegadas e o chão percorrido constituíam, dessa forma, uma espécie de limbo, um não lugar, uma transição imprecisa entre sua terra de origem, Adam's Rib, e seu destino final, Two-Town Post. Tratava-se de um território mutante, de uma paisagem viva e selvagem que se recusava a ajustar-se às formas dos mapas bidimensionais dos colonizadores, dialogando, por outro lado, com as memórias mais profundas das personagens, com a história inscrita em suas células que ainda ecoava a absorção de minerais da terra e a eliminação de oxigênio. Através dessa travessia, Angela finalmente consolidou seu aprendizado de navegar em águas limítrofes sem se deixar sucumbir, o que representava, em última instância, sua única possibilidade de sobrevivência.

\footnotetext{
20 "[A]s the land and soundless mists passed by".

21 "It was this gap in time we entered, and it was a place between worlds".

22 "There were no sharp distinctions left between darkness and light. Water and air became the same thing, as did water and land in the marshy broth of creation".
} 
De acordo com Arnold,

a cura se encontra no processo de ver duplamente, na habilidade de visualizar e vivenciar a fenda de separação e as cicatrizes que a fecham, tanto como ferida, quanto como a plenitude da conectividade, de viver entre a alegria e a tristeza, a razão e a emoção, a matéria e o espírito ${ }^{23}$ (ARNOLD, 2001, p. 56).

Nesse sentido, Angela aprendeu a mover-se nos espaços entre dois mundos diferentes - o tradicional e o moderno, o humano e o não humano etc. - sem se deixar submergir. Hannah, sua mãe, sucumbiu e seu espírito virou gelo, ou seja, água petrificada, estagnada, que não mais corre e não mais se transforma - água morta, em outras palavras. $\mathrm{O}$ ato de tornar-se água vivenciado por Angela, em total oposição à mãe, deu-se no sentido do movimento, da integração, da incorporação de características como a dissolução e a fluidez:

Com a janela aberta, eu vivia submersa em água. Não havia separação entre nós. Eu sabia de pronto o que era a água. Ela era o que tinha sido neve. Ela passara por entre velhas florestas, agora extintas. Era a doçura do leite e do milho e havia viajado através das vidas humanas. Era sangue derramado no chão. Parte dele era o sangue dos meus antepassados ${ }^{24}$ (HOGAN, 1997, p. 78).

As experiências liminares, consequentemente, constituem a essência de Solar Storms e desempenham um papel significativo na transformação de Angela. Segundo Shoemaker, "a liminaridade é útil para explicar o papel do ritual em qualquer sociedade e os deslocamentos causados por pessoas ou objetos que não se encaixam com facilidade em uma categoria"25 (SHOEMAKER, 2002, p. 60). A própria identidade de Angela, por exemplo, emerge de um ponto

\footnotetext{
23 " $[\mathrm{H}]$ ealing lies in the process of seeing doubly, the ability to see and experience the gap of separation and the scars that close it as both wound and the fullness of connectivity, to live in the between of joy and pain, reason and emotion, matter and spirit".

24 "With the window open, I lived inside water. There was no separation between us. I knew in a moment what water was. It was what had been snow. It had passed through old forests, now gone. It was the sweetness of milk and corn and it had journeyed through human lives. It was blood spilled on the ground. Some of it was the blood of my ancestors".

25 "Liminality is useful for explaining the role of ritual in any society and dislocations caused by people or objects who do not easily fall within a category".
} 
localizado entre categorias: ela é uma mestiça de cabelos vermelhos e pele escura, nascida de uma mãe também mestiça e de um pai desconhecido. Ela viaja para Adam's Rib em busca de seu passado, constantemente descrito como sendo um local de encontro de água e terra, e onde os antigos diziam que "terra e água haviam se unido num velho pacto, agora rompido"26 (HOGAN, 1997, p. 21).

As evidências da criação estão em todos os lugares, com frequentes recorrências a imagens de pântanos e áreas alagadas rodeadas de mosquitos e musgos que se definem, essencialmente, como espaços liminares entre terra e água. São locais que ressoam os primórdios da vida, os primeiros organismos surgidos, os tempos em que os continentes ainda não haviam sido cortados pelo oceano e formavam, consequentemente, um todo único. A paisagem daí resultante, portanto, carrega fortes marcas da criação, e o faz de tal forma a apresentá-la como um evento tão vivo, tão ativo e tão presente quanto a atual construção da barragem em Two-Town Post ou as histórias de exploração e abuso vividas pelas personagens.

Bastante significativo nesse aspecto é também o presente que Angela recebe de Dora Rouge, sua bisavó, algumas semanas após sua chegada a Adam's Rib. Trata-se de um pequeno sapo petrificado em âmbar que vem, desde muito, sendo passado de uma geração a outra pelas mulheres da família. Essa resina fóssil pode ser entendida através do conceito de liminaridade, em diversos níveis. Em primeiro lugar, o sapo é um animal que habita um espaço transicional, intercalando uma vida aquática com outra terrestre. Segundo uma perspectiva evolucionista, os anfíbios representam especificamente os primeiros animais que deixaram as águas para se aventurar em uma existência também sobre a terra. Eles se encontram num ponto limítrofe da classificação biológica que impede seu encaixe perfeito em qualquer definição fechada, deslocando-se entre categorias sem limitar-se a nenhuma delas. Além disso, a perpetuação desse sapo em específico através dos tempos deu-se em razão de seu congelamento em meio ao âmbar - uma resina produzida pelas árvores, que, como todas as outras plantas, crescem e se alimentam da terra -, sendo posteriormente encontrado pelos ancestrais das personagens em um local submerso em

26 " [L] and and water had joined together in ancient pact, now broken". 
água. O presente de Dora Rouge é, portanto, permeado figurativa e literalmente pelo conceito de liminaridade e, sobretudo, pelo motivo da união e convergência de elementos distintos a partir da qual novos produtos são criados. Por outro lado, ele também representa uma conexão entre o passado e o presente na medida em que se constitui como memória, como sobreposição de temporalidades: "Aquelas pessoas do sul falaram aos nossos ancestrais, 'Lembrem-se de nós quando tivermos partido', e colocaram isto sobre as mãos de uma velha de nome Luri, uma das minhas ancestrais, uma das suas"27 (HOGAN, 1997, p. 71). O sapo congelou-se em âmbar tal qual ele estava naquele específico momento, congelando também seu presente e subitamente alienando-se da passagem dos anos. Assim como a teoria de Einstein, diversas vezes mencionada por um dos personagens, ele representa 0 tempo inclinando-se de volta sobre si mesmo e conectando passado e presente, tribos atuais e seus ancestrais.

\section{A eletricidade como uma nova modalidade de colonização}

No romance, o movimento de dissolução de fronteiras dá-se também no campo político. Angela e os integrantes da sua e de diversas outras tribos encontram-se em situação de risco e engajam-se na luta contra um projeto hidrelétrico, que provoca danos terríveis a suas terras e modos de vida. Essa é uma batalha bastante delicada na medida em que opõe perspectivas fundamentalmente distintas sobre o que é a natureza e como o ser humano se relaciona com ela. Dentro do sistema de pensamento ocidental, a natureza é concebida como o lado passivo de uma relação dualística estabelecida com a cultura, vista como a transformação ativa da paisagem. Tal visão hierárquica, contudo, diverge profundamente das concepções nativo-americanas que Angela aprende com suas avós, de acordo com as quais tudo é igualmente vivo, sagrado e parte ativa no movimento constante de criação. A água, assim como todos os outros elementos constituintes da natureza, compartilha com o ser humano o fato de ter vontade própria. A construção das

\footnotetext{
27 "Those people from the south told our ancestors, 'Remember us when we are gone', and they placed this into the hands of an old woman named Luri, one of my ancestors, one of yours".
} 
CAROLINE GARCIA DE SOUZA e MARTA RAMOS OLIVEIRA-Dissolução de fronteiras...

represas requer a mudança arbitrária dos cursos dos rios, representando, nesse sentido, um ato de violação de seu desejo e a utilização inversa de seu poder, na medida em que rompe com a ordem natural das coisas. A inversão, aliás, era uma das armas mais perigosas do homem branco: "Invertendo a verdade, eles nos chamavam de terroristas. Se havia maldade nesse mundo, ela era isso, eu pensava. A inversão"28 (HOGAN, 1997, p. 283). A efetivação de tal empreendimento, portanto, afeta o ecossistema de forma direta e drástica, estendendo-se a territórios longínquos e prejudicando diversas comunidades, como as mulheres já podem perceber durante sua viagem. A luta travada por Angela, suas avós e tantos outros indivíduos era, sobretudo, uma luta político-ideológica pela dissolução das falsas fronteiras criadas pelo homem branco, como a que opõe o ser humano e o restante da natureza, e que se configura, em última instância, como o ponto de origem dessa e de muitas outras questões.

A construção das hidrelétricas tem por fim a produção de energia elétrica. Através da eletricidade, uma enorme gama de falsas fronteiras é ativada. Sua existência requer, por exemplo, a condensação de uma grande quantidade de energia dentro do espaço restrito de um cabo a fim de se produzir um tipo artificial de iluminação. No romance, a chegada das ideias de Thomas Edison ao território dos índios FatEaters $^{29}$ é descrita como representando uma nova modalidade de colonização, mais sutil e, por isso mesmo, potencialmente mais perigosa. A instauração da luz elétrica disparou uma série de desequilíbrios, afetando principalmente a relação entre o dia e a noite e intensificando as fronteiras que separam os espaços internos e externos. O sol, antes o instrumento de orientação por excelência, perdeu sua centralidade no estabelecimento das atividades diárias visto que a eletricidade, agora, estendia a disponibilidade de luz para muito além do entardecer, quase que extinguindo a possibilidade de mergulho numa escuridão total. A luz artificial passou a invadir cada canto das casas e a revelar detalhes nunca antes percebidos:

\footnotetext{
28 "Reversing the truth, they would call us terrorists. If there was evil in the world, this was it, I thought. Reversal".

${ }^{29}$ Nome pejorativo atribuído pelos brancos, no romance, a uma tribo (ficcional) que se identifica como the Beautiful Ones (os Belos).
} 
Com a chegada dessa luz, os cantos escuros e sem janelas no interior das casas agora mostravam a necessidade de limpeza ou de pintura. O chão foi exposto ao escrutínio. Homens e mulheres esfregavam lugares que haviam sempre estado na sombra. Paradas diante de espelhos, as pessoas olhavam-se a si próprias como pela primeira vez e se desapontavam com as linhas de expressão, as marcas e as cicatrizes quenunca antes tinham percebido ${ }^{30}$ (HOGAN, 1997, p. 267).

As superfícies foram sendo (re)descobertas de uma maneira nunca antes vivenciada, demandando um alto nível de atenção e cuidado e intensificando os limites do corpo e da casa. Era um novo modo de vida que se adquiria, mas o preço por ele pago não era qualquer um: a iluminação elétrica impôs-se às custas tanto da escuridão - e, figurativamente, da possibilidade de mergulhar em experiências interiores mais profundas - quanto das terras e rios de seus ancestrais. Todo um modo de vida se altera, expondo a população à dependência de um sistema invasivo e colonialista.

\section{Considerações finais}

É possível afirmar que Solar Storms apresenta uma jornada de integração e religação dos mundos humano e além do humano, bem como dos conhecimentos tradicionais e novos. A viagem em direção a um modo de vida e pensamento holístico se dá através de construções discursivas que integram uma consciência cosmológica e a experiência histórica, aproximando essas duas esferas aparentemente separadas e transformando-as em um modo de ser e estar na Terra. Da mesma forma, a dissolução de fronteiras, sobretudo das falsas divisas criadas pela visão ocidental, é apresentada como o principal caminho através do qual se pode alcançar uma verdadeira conectividade e vivenciar plenamente a experiência da criação.

A cura de Angela, portanto, realiza-se no seu aprendizado de

\footnotetext{
30 "With the coming of this light, dark windowless corners inside human dwellings now showed a need for cleaning or paint. Floors fell open to scrutiny. Men and women scrubbed places that had always before been in shadow. Standing before mirrors, people looked at themselves as if for the first time, and were disappointed at the lines of age, the marks and scars they'd never noticed or seen clearly before".
} 
desconstruir fronteiras e encontrar maneiras de navegar nesse espaço transicional, costurando os mundos que, a princípio, a separavam de si mesma, das suas origens e do seu lugar de direito. Ao longo da jornada, ela finalmente consegue se conceber como parte integral de um todo maior que alimenta sua existência de sentido. Ela percebe que é como o sapo congelado em âmbar, como tempestades solares, emergindo de um passado remoto e viajando pelo tempo e pelo espaço, atravessando gerações para finalmente encontrar o presente, carregando ainda a matéria e a memória dos primórdios.

\section{Referências bibliográficas}

ARNOLD, Ellen. Maps over the face of god: remapping epistemologies in Linda Hogan's Solar Storms. Paradoxa, Washington, v. 15, p. 49-60, 2001.

CASTOR, Laura. Claiming place in wor(1)ds: Linda Hogan's Solar Storms. MELUS, Fargo, v. 31, n. 2, p. 157-180, jun. 2006.

HOGAN, Linda. Solar Storms. New York: Scribner Paperback Fiction, 1997.

LAKOFF, George; JOHNSON, Mark. Metaphors We Live By. Chicago: University of Chicago Press, 1980.

SHOEMAKER, Nancy.Categories, In: SHOEMAKER, Nancy (Org.). Clearing a Path: Theorizing the past in Native American Studies. New York: Routledge, 2002.

WALTER, Roland. Unwriting manifest borders: on culture and nature in Leslie Marmon Silko, James Welch and Linda Hogan. Acta Scientiarum, Maringá, v. 28, n. 1, p. 7-11, 2006. 